\title{
Stimulating innovation: Managing peer interaction for idea generation on digital innovation platforms
}

\author{
$\mathrm{Mu}$ Yang, Chunjia Han \\ Department of Systems Management and Strategy, University of Greenwich, UK \\ Abstract
}

\begin{abstract}
This study investigates user behaviours in online innovation communities which are enabled by digital technologies, to obtain an understanding of the relationship between user's social interaction and their innovation contribution. The new type of innovation communities enable firms to crowdsource ideas from their users for developing new products and improving existing ones, and to facilitate the interactions among users. From an empirical study which collects a large-scale, quantitative data set from Microsoft's Idea platform of Business Intelligent products, this paper focuses on the amount and diversity of users' social interaction particularly their commenting behaviours on the platform, and uses the number of posted ideas and the number of implemented ideas to capture users' contribution to the firm's innovation development. The findings indicate that the amount of user interaction is positively related to the number of implemented ideas, but has an inverted U-shaped relationship with idea number. Moreover, diverse user interaction encourages idea posting, but is negatively associated with the number of implemented ideas. The findings should provide managerial guidance to firms on incentivizing and managing user interaction in online communities in order to improve firms' innovation development.
\end{abstract}

Keywords: open innovation, digital platform, user interaction, crowdsourcing 


\section{Introduction}

Involving customers into firms' innovation processes can help to avoid innovation failure and contribute to innovation success (Schemmann et al., 2016). The development of digital technologies has provided a cost-effective and richer way for a firm to enable large number of customers to participate in its innovation process (Sawhney et al., 2005). Relying on digital technologies, firms build online platforms where dialogues between the firms and their customers are developed. The increase in digitalization and decrease in the cost of communication for ordinary customers have led to the exponential growth of such online platforms (Mahr \& Lievens, 2012), which have been used for crowdsourcing and generating new ideas about products, services and processes by large firms (West \& Lakhani, 2008). According to Howe (2006), "crowdsourcing is the act of taking a job traditionally performed by a designated agent (usually an employee) and outsourcing it to an undefined, generally large group of people in the form of an open call". Crowdsourcing ideas online could operate in different ways depending on how a job is outsourced to people. In the context of innovation, crowdsourcing solutions to firm challenges can take the form of a one-time contest (Terwiesch \& Xu, 2008), or a continuous open call which allows individuals generate ideas repeatedly over time (Bayus, 2013). A one-time contest normally runs for a certain time period to search for new ideas or solutions for fairly specific questions or problems. A long-term open call can generate a large number of ideas of various qualities concerning an often rather broad topic (Schemmann et al. 2016). Online platforms in which the latter process often takes place are called online (user) innovation communities (Hoornaert et al. 2017; Bayus, 2013). People who contribute in online innovation communities (OICs) are called users. Users are invited to contribute to activities related to product innovation, and the contribution includes proposing new ideas as well as commenting on the ideas of others (Gebauer et al., 2013). This facilitates users to share ideas and develop solutions by building on other's work (Dahlander \& Frederiksen, 2012). 
OICs have gained popularity in attempting to involve customers in a firm's innovation process (Gebauer et al., 2013). The analysis shows that more than $80 \%$ of high-tech firms listed in the S\&P 500 index have established OICs to benefit from customers' inputs (Mahr \& Lievens, 2012). Indeed, examples of such OICs can be found in different sectors, such as Dell's IdeaStorm and Starbucks' MyStarbucksIdea, which have been launched to collect user ideas since 2007 and 2008 respectively. More than 23,000 ideas have been collected by Dell via IdeaStorm (Schemmann et al., 2016), and both Dell and Starbucks reported that they had already implemented a few hundred of user ideas out of the collected ideas (Bayus, 2013). Other firms such as Microsoft, IBM, BMW and P\&G have also increasingly invested in OICs (Mahr \& Lievens, 2012, Fiedler \& Sarstedt, 2014) in order to crowdsource new ideas from their customers.

Although the use of OICs has become popular in practice, the majority of research on idea crowdsourcing focus on one-time contests, little research has been conducted on OICs (Schemmann et al., 2016; Bayus, 2013). Existing research on OICs mainly focus on the effect mechanism of OICs on innovation outcomes, such as methods of detecting and evaluating user ideas (Hoornaert et al., 2017, Bayus, 2013). As platforms enable interactions among users, the success of OICs should be highly related to such social behaviours of users. Although a few studies investigated the influence of user interactions from the perspective of the importance of receiving other users' feedback, such as the application of other users' feedback as a predictor of idea implementation (Hoornaert et al., 2017) and the effect of other users' feedback on the stimulation of a ideator's innovation in OICs (Ogink \& Dong, 2017), how ideators' peer interaction affects their innovation performance in OICs is still unclear.

This study addresses this research gap by investigating the relationship between ideators' peer interaction and their innovation contribution in OICs. In this paper, an empirical study is conducted which collects a large-scale, quantitative data set from the Microsoft online innovation community, including 5468 users, and 11985 ideas as well as associated interaction data between September 2014 (when the platform was 
launched) and September 2018. We focus on the amount and diversity of ideators' social interaction particularly their commenting behaviours, and use the number of posted ideas and the number of implemented ideas to capture ideators' contribution to the firm's innovation development. The findings indicate that the amount of ideators' peer interaction is positively related to the number of their ideas implemented by the host firm, but has an inverted-U relationship with the number of idea that they generated. The diversity of user interaction is positively related with idea number, but negatively related with the number of implemented idea.

The findings in the research extend existing literature in terms of understanding the relationship between user interaction and innovation outcomes. Part of the results we received have challenged the conclusions of the prior research (Bayus, 2013) and enriched our knowledge about how users' diverse interaction affects their innovation performance in OICs. While some of our conclusions are in line with previous studies (Franke \& Shah, 2003; Bullinger et al., 2010), they provide a more precise understanding on the relationship between users' peer interaction and innovation performance in OICs. In addition, our study demonstrates that the stimulation effect of diverse interaction on ideation effort exists in online communities. Overall, this research will help firms incentivize and manage user interaction in OICs in order to improve firms' innovation development.

\section{Theoretical Background and Hypotheses De- velopment}

Overall, studies on OICs mainly focus on two general topics (see Table 1). Most existing studies on OICs are interested in identifying the common characteristics of implemented ideas in order to create models for the prediction of idea adoption (Ma et al., 2019; Hoornaert et al., 2017; Li et al., 2016; Schemmann et al., 2016). Considering 
the huge number of crowdsourced ideas in OICs, research on this topic may have significant contributions on industry practice by assisting firms in efficiently processing ideas in OICs. Another popular topic on OIC research is about the development of valuable innovation knowledge in OICs. The effects of different types of human roles (e.g., lead users and internal employees) on innovation generation have been examined in previous studies (Yan et al., 2018; Mahr and Lievens, 2012). Moreover, research on both topics have identified users' feedback as an important characteristic of OICs. Receiving other users' feedback has been found as a predictor of idea implementation (Hoornaert et al., 2017), and a stimulator for an ideator's innovation in OICs (Ogink and Dong, 2017). However, receiving other users' feedback is only one type of interaction in OICs. OICs as social medias allow the development of peer interactions among users. Peer interactions in OICs create an attractive means to tap diverse expertise to be recombined into innovations (Dahlander \& Frederiksen, 2012). Therefore, it is worth examining that how ideators' interaction with others affect their own innovation performance in OICs.

Studies on customer interaction in media context ranged from radio and television, for example, Palmgreen et al. (1981); Perse \& Courtright (1993), to cell phones and the Internet (Kaye \& Johnson, 2002, Parker \& Plank, 2000: Stafford et al. 2004). Most studies contributed from two angles which were interactions with the media itself, and with each other through media. The underlying theoretical implications in these studies were found to be similar within the context of the traditional types of media, such as radio and television, but the specific benefits of the consumer interaction associated with the Internet context were observed different (Nambisan \& Baron, 2007). OICs as an Internet-mediated context are built on voluntary participation and often lack central hierarchical authority (Magee \& Galinsky, 2008). Moreover, users in OICs have more freedom to choose which interactions they participate with and how much time they spend on their preferred topics (Dahlander \& O’Mahony, 2011). Therefore, it is necessary to study the behavior of peer interaction and how it affects the innovation 
performance in an OIC context.

\subsection{Effects of Interaction Amount on Innovation Perfor- mance}

From the perspective of the attention-based view, attention is one essential element for initiating idea integration in groups. Individuals must attend to the ideas shared by others in order to discover new perspectives (Ocasio, 1997). In addition, individuals' idea integration depends on the extent and quality of attention allocated to the ideas shared by others (H. A. Simon \& Barnard, 1947). Further to innovation communities, peer interactions such as commenting on others' ideas can be applied to represent the attentions that ideators paid to other users' ideas. Prior research shows that interaction and idea exchange among individuals can facilitate the retrieval of relevant and diverse knowledge during the idea generation process (Hinsz et al., 1997; Kohn \& Smith, 2011). More specifically, idea sharing and the exposure to other's creative ideas have been observed as important experience that can enhance one's own creativity, which eventually leads to an increase in the number of new ideas proposed by individuals (Paulus \& Yang, 2000; Nijstad \& Stroebe, 2006). This is consistent with a number of studies related to the creative processes and idea generation within communities. For example, Bullinger et al. (2010) found via a study on a community-based innovation contest, that giving attention to others' ideas is an important characteristic for potential successful innovators.

Online communities have been serving as a venue for users to exhibit their productrelated knowledge and problem-solving skills (Nambisan \& Baron, 2007). In online communities, users share information via posting, and the trust among users is engendered through ongoing peer interaction (Figallo, 1998). Commenting on each other's ideas, which is the main form of peer interactions serves as the pipes for information sharing as well as the prisms that induce differentiation between various users (Podolny, 
2001). Moreover, continuous user interactions generate and share collectively valuable knowledge within online communities (Rothaermel \& Sugiyama, 2001). Users who acquire such product-related information can develop better understanding on product from their interactions in the communities. This is particularly so in the context of technology-based products which are characterized by rich and complex set of features (Nambisan \& Baron, 2007). Interacting with others via online comments has been shown to promote active and critical thinking (Anderson et al., 2001), and can deliver positive reaction by providing people "Aha" moments (Nambisan \& Baron, 2007). Therefore, following the attention-based view, it sounds reasonable to assume that paying attentions to other users' ideas via commenting should be positively associated with the creation of ideators' new ideas.

However, the attention-based view is developed based on the logic of attention being a scarce resource (H. A. Simon \& Barnard, 1947, H. Simon \& March, 1958). The amount of attention people can allocate to deal with information processing activities is limited (Ocasio, 1997). Furthermore, information processing is time consuming because information needs to be noted, encoded and interpreted to be useful (Dahlander \& O'Mahony, 2011). When information is overload to people's attention, the benefits from collected information can be reduced, because people's behaviors may be constrained by the collected information (Uzzi, 1997). In other words, too much information received from environments can increase the time cost on individuals' innovation activities. Large number of interactions, such as peer interaction in online communities may bring negative influence on individuals' outcomes of new ideas and solutions (Koput, 1997), as too much information can be harmful to innovation performance (Girotra et al., 2010). Therefore, the amount of user interactions would affect individuals' outcomes of new ideas. Cattani and Ferriani (2008) found that an intermediate position between the core and the periphery of social structure in an online community is a favourable one for individuals to achieve creative results, which may indicate that having an intermediate level of peer interaction in online communities 
can bring more benefit on people's innovation performance. Therefore, the following hypothesis can be used to test the relationship between the number of interactions and idea quantity.

H1. There is an inverted U-shaped relationship between the number of user interactions and the number of new ideas that an individual proposed.

In the context of OICs, the enhanced attention to others' ideas can be realized by continued interaction with others (i.e., commenting) on proposed ideas. The peer interaction in the virtual media environment can bring users cognitive benefits reflecting product-related learning - that is, better understanding and knowledge about products, the underlying technologies, and the usage (Nambisan \& Baron, 2007). These productrelated learning might be especially important for the development of innovation on technology-based products. More specifically, this experiential knowledge obtained from the interactions in online communities would enable users to better understand product-related issues (Algesheimer et al., 2005), and address present innovation challenges more effectively (Nambisan \& Baron, 2007). Therefore, the literature suggests that the quality of an individual's own outputs can be benefited from her enhanced attention to others' ideas (Smith, 2003). For example, in Franke \& Shah (2003)'s study on sports-related communities, they found that the individuals who spent significantly more time within the community contributed more on the improvement of existing products and the development of new products. Following the above discussion, the next hypothesis is developed in this research.

H2. There is a positive relationship between the number of user interactions and the number of implemented ideas that an individual proposed. 


\subsection{Effects of Interaction Diversity on Innovation Perfor- mance}

Prior studies on innovation process and idea creation have demonstrated that peer interaction on diverse ideas has a positive effect on idea generation Amabile, 1996; Perry-Smith \& Shalley, 2003). It is because giving enhanced attention to diverse ideas stimulates the generation of new ideas especially when individuals are self-motivated to attend to the innovation process (Rietzschel et al., 2007; Kohn et al., 2011). Osborn (1953) in his brainstorming study disclosed that interacting with diverse others can stimulate associations in memory that lead to higher quality ideas. It is worth noting that the interaction investigated in Osborn's study refers to the traditional face-to-face discussions which have been widely studies in the area of brainstorming.

It is widely believed that the stimulation effect of diverse interaction on ideation effort exists in online behaviours as well. User interactions in OICs can relate to different types of product knowledge: product-technology knowledge, product-market knowledge, or product-use knowledge (Nambisan \& Baron, 2007). It is often that an OIC includes multiple categories focusing on different functions or aspects of products and services from the host firm. User are allowed to select the categories they would like to participate and contribute into. A number of studies have shown that users exhibit different participation behaviours: some users choose to be active in only one category while some actively participate in more than one category (Carlile, 2004; Bayus, 2013). Participating in multiple categories allows users to span across boundaries between each category, so that they are able to transfer, translate and transform experiences from one group to another (Carlile, 2004). The different categories of communities represent different "thought worlds" (Dougherty, 1992) that expose people to diverse knowledge. People who interact with multiple categories in a community can develop different expertise, which provide them fresh angles for tackling problems and creating solutions (Burt et al. 2005). Therefore, this research developed the follow- 
ing hypothesis to test whether there is a positive relationship between the diversity of users' commenting activities and the number of new ideas that they proposed.

\section{H3. There is a positive relationship between the diversity of user interaction and the number of new ideas that an individual proposed.}

Research has recognized that drawing out knowledge from diverse sources can help people to discover and adapt new ideas and solutions (Jeppesen \& Lakhani, 2010). Users in online communities who comment on a diverse set of others' ideas should develop a better understanding on current problem, which leads to high quality ideas that are more likely to be valuable and thus be implemented by firms (Bayus, 2013). However, spanning to diverse areas may turn detrimental, as it diverts people's attention from generating ideas and makes connecting information difficult (Dahlander \& O'Mahony, 2011). Moreover, the time required to reciprocate interactions becomes longer, making it difficult for individuals to focus on the direction that they are truly good at (Csikszentmihalyi, 1997) and thus leaving individuals less able to engage in creative thinking (Perry-Smith, 2006). In this situation, interactions on a diverse set may not lead to high quality ideas. This is particularly the case in OICs which usually get involved hundreds of thousands of customers to post and comment ideas. A huge number of new ideas and comments under each category can be generated quickly in a short time period. It is very time consuming for individuals actively participating and getting deeply involved into peer interactions in every category. Research generally recognizes that only a small proportion of ideas posted by users can be selected and implemented by host firms, through observing a number of popular OICs (Bayus, 2013). It is not surprising as users need to collect enough information to be able to develop high quality ideas which have greater potential to be adopted by host firms. One way to collect enough information is via deep involvement in the communities. However, OICs create a crowed information environment, which significantly increases the cost of information processing and absorbing across diverse areas. Therefore, the corresponding high diversity of user interactions in OICs could be harmful to the quality of 
individuals' innovation outcomes, which reduces an idea's implementation possibility. In other words, the diversity of user interactions tends to be detrimental to the idea implemented number. This leads to the fourth hypothesis:

\section{H4. There is a negative relationship between the diversity of user interac- tion and the number of implemented ideas that an individual proposed.}

\section{Methodology}

\subsection{The dataset}

The study uses publicly available data from an online idea crowdsourcing platform founded by Microsoft, specifically for the Power Business Intelligence (PowerBI) software products. The platform brings the firm and its users together, collecting ideas directly from PowerBI users on improving existing products and services as well as developing new ones. To participate, users join the platform free of charge by creating a profile with an email address. The platform assigns a default username, i.e., anonymous if users do not provide it when accounts are created, however, users are allowed to provide later on. Similar to other popular crowdsourcing platforms, such as Dell IdeaStorm and MyStarBucksIdea, the demographics of users are not collected, and usernames are the identifiers to determine which idea is contributed by whom.

When posting an idea, users are required to give a title and a description, as well as selecting a category that the idea belongs to. There are 19 categories (e.g., Reports, APIs and Embedding, Dashboard, etc.) in the collected data, two new categories have been added after our data collection date. As only 22 ideas (less than $0.14 \%$ of total ideas) fall into the new categories, our data are able to represent the characteristics of whole data. Besides posting ideas, users are able to interact with other users by voting whether they support an idea, and commenting on others' ideas.

The idea review team of Microsoft makes implementation decisions on the posted 
ideas in two phases. Firstly, the team reads ideas and identifies the ones that need to take action on. These identified ideas are assigned with a label to indicate their status. There are eight status categories, including backlog, under review, escalated, planned, started, consideration for backlog, not planned, and completed. Besides the status label, the team provides a comment to the user in order to explain why the label is chosen. The comment may also contain answers to queries if posted together with the idea. Note that as this comment is only provided once when the status label is assigned, it is separated from other comments the idea receives over time on the platform, in the form of an explanation to the status label. In the second phase, the review team works on the labelled ideas and adjusts the status labels if progress has been made. For instance, the 'under review' label of an idea can be replaced by 'started' if the idea is put into implementation process. If an idea gains priority after the review, the label 'escalated' will be assigned. Once the implementation is completed, ideas are assigned with 'completed' status. Unlike Dell IdeaStorm, there is no reward (e.g., money, badge) for users if their ideas get implemented.

The PowerBI platform received its first idea in September 2014. In order to stabilize the interaction around a new idea, we crawled data on all of the ideas posted between September 2014 and June 2018, without collecting ideas posted in the following three months (i.e., July, August, and September 2018). This is because the interaction around new ideas are observed to be stabilized within three months. During the data collection period, 11985 ideas were posted, out of which 559 ideas had been implemented. The implementation ratio is $6.0 \%$, which is consistent with other idea crowdsourcing platforms (Di Gangi \& Wasko, 2009). As data on the ideas contributed by users with username anonymous cannot be distinguished from each other, we dropped the ideas posted by anonymous users, allowing the study on the level individual users. The number of ideas becomes 9243, and 5469 users are involved. The number of comments from all these users is 5019 out of the total 30940 comments collected. Note that the users who never contribute ideas but only comments are not 
included in the study. This is because without the idea contribution, it is not possible to examine how the individual's commenting behaviours is related to his/her idea contribution. As usernames are not recorded on votes, it is not possible to determine which vote is contributed by whom. Therefore, we focus on the commenting behaviours as the main interaction among users in this study.

Descriptive information on the PowerBI user population is presented in Table 2. The majority users, i.e., 3909 (or $71.5 \%$ of all users) posted only one idea on a single occasion. Among the 3909 ideas, 196 ideas had been implemented. For users who contributed more than one ideas (i.e., serial contributors), 1559 individuals contributed 5334 ideas. Moreover, 1305 out of the 1559 users had zero idea implemented, while 254 individuals had 363 ideas implemented. Since the study aims to understand the relationship between the interaction behaviours among users and idea contribution, Table 3 summaries the commenting activities of PowerBI users who has posted at least one idea. As indicated in Table 3, almost 71.2\% (i.e., 3892/5468) of users had not provided any comment. The collected 5019 comments are contributed by the rest 1576 users. Among the 1576 users, $87.4 \%$ of them contributed comments between one and five, amounting to 2573 comments. The remaining 199 users posted over five comments respectively, amounting to 2446 comments.

\subsection{Measurement}

We used measures at the individual level to capture users' idea creation and interaction behaviours. Observing that count measures have been used to capture users' innovation behaviours (Hofstetter et al. 2018; Schemmann et al., 2016), the dependent variables measure user's innovation capability from two aspects: the number of ideas contributed by a user and the number of implemented ideas contributed by the user. As it can take some time to complete the implementation of an idea in practice, the implementation status of an idea is coded as 1 if the status label assigned by Microsoft review team 
is 'completed', 'started', or 'escalated'; otherwise, it is coded as 0. The dependent variable number of implemented ideas counts the total number of ideas which receive the code 1 .

The measures of user interaction on the PowerBI crowdsourcing platform is based on a user's commenting behaviours over posted ideas, including his/her own ideas. This study focuses on commenting rather than voting behaviours because votes cannot be traced back to users whereas usernames are associated with every comment. The independent variable number of interactions (see H1, H2) is measured as the total number of comments posted on the platform by a user during the data collection time period. The value of the variable becomes zero if no comment had been posted by an user during the data collection time period.

The independent variable interaction diversity (see H3, H4) captures the diversity of comments on posted ideas over different idea categories. We use Shannon entropy which has been exploited as a diversity measure for a number of applications (Harrison \& Klein, 2007; Bayus, 2013), to measure the independent variable interaction diversity as an entropy over the 19 idea categories. More formally, we calculate the interaction diversity as $-\sum_{j=1}^{n} p_{j} \log p_{j}$, where $p_{j}$ is the proportion of the number of comments posted by an user in category $j$ to the total number of comments posted by the user, and $n$ is the number of idea categories. We have $n=19$ in this study. The entropy measure calculates the comment diversity into a range of $[0,1]$, and the greater the value, the more diverse in terms of users commenting behaviours.

Table 4 provides the descriptive statistics for the dependent and independent variables, and Table 5 shows the correlations. In our data, an average of 4.4582 ideas were posted by individual users and the maximum number of ideas by a single user was 45 . Among the posted ideas, 0.288 ideas were implemented on average while the maximum was 8 and minimum was zero. In terms of the interaction behaviours, an average of 2.975 comments were generated per user and the maximum was 49. The comment diversity on average was low, i.e., 0.139 indicating that users posted comments in limited 
number of idea categories on the average. As suggested by Table 5 , the variables are correlated at the significant level of $p<0.001$.

\subsection{Analysis and results}

\subsubsection{H1 test: inverted U-shaped relationship between number of interactions and idea quantity}

We test $\mathrm{H} 1$ with an hierarchical regression analysis approach. Three regression models are developed and are shown in Eqs. 1, 2 and 3, where $y_{q t y}$ represents the idea quantity and $x_{N o}$ represents the number of interactions.

$$
\begin{aligned}
& y_{q t y}=\beta_{0}+\beta_{1} x_{N o}+\epsilon, \\
& y_{q t y}=\beta_{0}+\beta_{1} x_{N o}+\beta_{2} x_{N o}^{2}+\epsilon, \\
& y_{q t y}=\beta_{0}+\beta_{1} x_{N o}+\beta_{2} e^{x_{N o}}+\epsilon,
\end{aligned}
$$

where $y_{q t y}=$ number of posted ideas, and $x_{N o}=$ number of posted comments.

Eq. 1 aims to evaluate the linear relationship between the number of interactions and the number of ideas contributed on the platform, whereas Eqs. 2 and 3 focus on the nonlinear relations. More specifically, Eq. 2 includes a quadratic term for the number of interaction, i.e., $x_{N o}^{2}$ and Eq. 3 adds the exponential term $e^{x_{N o}}$. The validation results of the hierarchical regression analysis are presented in Table 6 .

We compare the three models to evaluate whether the number of comments has an inverted-U shape relationship with the number of posted ideas. In Model 1, the linear effect is positive (0.788) and significant. In Model 2, both the linear and quadratic effects are significant. The linear effect is positive, i.e., 1.118, and the quadratic term has a negative effect, i.e., -0.011 . Moreover, the value of adjusted R-squared increases from 0.641 to 0.665 . In Model 3, both the linear and exponential effects are significant. 
Similarly, the linear effect is positive while the exponential effect is negative. The adjusted R-squared increases further to 0.666. Therefore, we can confirm the nonlinear relationship between the number of interactions and the idea quantity, and $\mathrm{H} 1$ is supported as Model 3 presents an inverted-U shape relationship.

\subsubsection{H2 test: positive relationship between number of interactions and the number of implemented ideas}

One methodological challenge to test $\mathrm{H} 2$ is the presence of excess zeros observed in the dependent variable number of implemented ideas which is measured as the number of implemented ideas. More specifically, as there are only 559 out of 9243 ideas had been implemented, a large number of users have zero idea implemented. Ordinary count models, such as Poisson and Negative Binomial models, are usually insufficient to account for the preponderance of zeros in a count data distribution (Greene, 1994). Zero-inflated Poisson (ZIP) regression and zero-inflated negative binomial (ZINB) regression models have gained considerable recognition in the analysis of count data with excess zeros (Cheung, 2002, Heilbron, 1994; Simons et al., 2006). ZINB is more appropriate for our study than ZIP because it has been observed that ZIP parameter estimates can be severely biased if the non-zero counts are over-dispersed. As shown in Table 4, the standard deviation of the number of implemented ideas is greater than its mean, indicating the presence of over-dispersion in the dependent variable.

To test H2, a ZINB regression model is used, which contains two processes with a mixture distribution: the modelling of the observed over-dispersion via the negative binomial component, and the modelling of the extra zeros via the logistic component. The first process has a distribution where the number of implemented ideas can be any integer including zero, and the focus is on the count portion. The distribution of the second process is for the zero counts that the number of implemented ideas of an user is always zero. More specifically, the involved logistic model is to investigate the 
likelihood of an observation being a zero-value, that is, a posted idea is not categorised as implemented due to that it has not been considered by the review team as ideas that need to take action on. The distribution of the ZINB model is given by the following equations.

$$
\operatorname{Pr}\left(y_{q l t y}=j\right)= \begin{cases}(1-p) \frac{\Gamma(j+\tau)}{j ! \Gamma(\tau)}\left(1+\frac{\lambda}{\tau}\right)^{-\tau}\left(1+\frac{\tau}{\lambda}\right)^{-j}, & \text { if } j=1,2, \ldots \\ p+(1-p)\left(1+\frac{\lambda}{\tau}\right)^{-\tau}, & \text { if } j=0\end{cases}
$$

where $y_{q l t y}$ is the dependent variable number of implemented ideas, measured as the number of implemented ideas, and $p$ is the probability that a posted idea had not been assigned a status label by the review team. Thus $1-p$ represents the probability that a posted idea received a status label and a count had been generated (including zero if the review team decided the idea is not worthy to be implemented after further review in the second review phase). Moreover, the parameter $\lambda$ represents the mean of the distribution, $\Gamma$ represents the gamma distribution of $\lambda$ in order to model the overdispersion, and $\tau$ is a shape parameter which quantifies the amount of over-dispersion. The details of the ZINB regression model can be found in the study by Greene (1994).

The model results of the ZINB regression analysis are presented in Table 7, specifically under Model 4. The coefficients for the variables in both negative binomial part and zero-inflated part are found to be significant at the 0.001 level. In viewing the results in Table 7, we find the number of comments is positively related to the number of implemented ideas. For every increase in the number of comments, the significant increase in the log form of the number of implemented ideas is 0.023 , and there is an decrease in the $\log$ form of the likelihood of being in the zero-implementation state, i.e., a negative coefficient -0.437 in the zero-inflated part.

Additional robustness analysis is conducted and displayed in Table 7 (Model 5), where an ordinary negative binomial regression analysis is conducted to examine the relationship between the number of comments and the number of implemented ideas. 
Although the estimation results are also significant with p-value at the level of 0.001 , the dispersion parameter decreases from 1.074 to 0.324 , and in the meanwhile the absolute value of log-likelihood increases, both indicating that Model 5 does not fit as well as the ZINB model (i.e., Model 4). We use the Vuong test to further compare the two models using the Kullback-Leibler information criterion (Vuong, 1989). The test results are presented in Table 8, which confirm that Model 4 is significantly closer to the true data. Therefore, H2 is supported.

\subsubsection{H3 test: positive relationship between comment diversity and idea quantity}

To test H3, we use the hierarchical regression analysis approach again, and the number of comments is included as a control variable. The nonlinear relation, particularly the exponential effect is considered in the models. The regression equations are shown in Eqs. 5, 6 and 7, where $y_{q t y}$ represents the idea quantity measured as the number of posted ideas, and $x_{d i v}$ represents the comment diversity calculated by the entropy measure. The hierarchical regression analysis results are presented in Table 5.

$$
\begin{aligned}
& y_{q t y}=\beta_{0}+\beta_{1} x_{N o}+\beta_{2} e^{x_{N o}}+\beta_{3} x_{d i v}+\epsilon, \\
& y_{q t y}=\beta_{0}+\beta_{1} x_{N o}+\beta_{2} e^{x_{N o}}+\beta_{3} x_{d i v}+\beta_{4} x_{d i v}^{2}+\epsilon, \\
& y_{q t y}=\beta_{0}+\beta_{1} x_{N o}+\beta_{2} e^{x_{N o}}+\beta_{3} x_{d i v}+\beta_{4} e^{x_{d i v}}+\epsilon .
\end{aligned}
$$

All the three models confirm that the independent variable comment diversity $x_{\text {div }}$ has a significant positive effect on the idea quantity (p-value at the level of 0.001). As shown in Table 5 , the quadratic term $(\beta=29.295)$ and the exponential term $(\beta=38.380)$ of the comment diversity are significant at the level of 0.001 . The adjusted 
R-squared increases from 0.667 to 0.671 when the quadratic and exponential term are added to the regression model. Both Model 9 (with the quadratic term) and Model 10 (with the exponential term) exhibit a convex curve. Based on these results, H3 is confirmed that the number of posted ideas marginally increases when the comments posted by users become more diverse.

\subsubsection{H4 test: negative relationship between comment diversity and the number of implemented ideas}

To test H4, we continue using the ZINB regression model because the number of implemented ideas presents excess zeros and over-dispersion. The number of comments is included in the analysis as a control variable. The analysis results are presented in Table 7. As shown under Model 6 of Table 7, the independent variable comment diversity is negatively related to the number of implemented ideas in the negative binomial part with the significant level at 0.05 . That is, for every increase of one unit in the diversity of comments posted by the user, the decrease of the log form of the user's number of implemented ideas is -0.357 . However, comment diversity has no relationship with the number of implemented ideas in the zero-inflated part because of the insignificant coefficient estimates shown in Model 6 of Table 7 . This result suggests that comment diversity is not significantly related to the zero-implementation of the posted ideas.

To valid the ZINB model, we conducted the Vuong test which compares Model 6 with Model 7. An ordinary negative binomial regression analysis was conducted for Model 7. As shown in Table 8, Vuong test results confirm that Model 6 significantly fits the data better than Model 7 with p-value at the significant level of 0.001. Moreover, the dispersion parameter of Model 7 is 0.355 as shown in Table 7 , indicating a high overdispersion level of data fitted in the model. On the contrary, the dispersion parameter of Model 6 is 1.151, showing that Model 6 fits data better. Therefore, based on the 
findings from Model 6, we can confirm H4.

\section{Discussion}

In this research, the social interaction among users in OICs is empirically investigated. Four years of panel data involving several thousand users who produced almost ten thousand ideas are studied in the context of Microsoft's ongoing OIC. This study disclosed how peer interactions among users in OICs affect individuals' innovation contribution. Two characteristics of user interaction are considered: the amount of interaction which is measured by the number of comments that an individual posted in community, and the interaction diversity which is captured by the entropy-based measure on the diversity of comments on ideas which belong to different categories. The innovation contribution is evaluated by the number of new ideas posted by an individual and the number of implemented idea out of the posted ideas. It is widely accepted that continuous interaction among customers can generate and share valuable knowledge (Rothaermel \& Sugiyama, 2001), which stimulates the production of new ideas crowdsourced from customers (Nambisan \& Baron, 2007). However, results we obtained from this research disclosed that the reality is much more complicated than existing studies suggested for OICs. There is an inverted-U shape relationship between the amount of user interaction and the number of new ideas generated by individuals. In line with common understanding and prior research, having interactions with others in OICs can contribute to the production of new ideas, but this does not happen all the time. Indeed, too many peer interactions may bring negative influences on individuals' innovation contribution in communities - a decrease in the number of new ideas generated by users. Unlike a firm's internal innovation process or financial rewarded crowdsourcing, OICs are built on voluntary participation (Magee \& Galinsky, 2008). More specifically, users allocate certain amount of their own time themselves on OICs, affected by elements such as their motivation (Bayus, 2013). Too much time 
consumed by overloaded peer interaction may cause limited time left for innovation activities such as new idea creation. As a result, the effect of user interaction on the number of new ideas produced by individuals exhibits an inverted-U shape. The findings in the research extend existing literature in terms of the understanding on the relationship between the amount of user interaction and the amount of innovation outcomes.

Furthermore, our results show that the amount of user interaction has a positive relationship with the number of implemented new ideas posted by individuals. This is in line with the findings of the study by Schemmann et al. (2016), who concluded that "the ideator's attention paid to other ideas positively influences the likelihood of an idea to be implemented". While similar findings were reported in a number of prior studies (Franke \& Shah, 2003; Bullinger et al., 2010), the results of our research provide a more precise description on the relationship between the amount of interaction and the number of implemented ideas. With a huge number of new ideas posted in OICs, only a small proportion of ideas can be finally implemented by host firms. A large number of users never have their ideas implemented. Our analysis indicates that, for such users, having more interactions with other users could help them improve the situation and start to get ideas implemented by firms. Moreover, for the individuals who already have at least one idea implemented, our research showed that the more interactions with other users, the more implemented ideas they may contribute. This is because individual users obtain valuable knowledge from others' ideas via peer interaction, which increases the quality of an individual's own outputs (Smith, 2003). As individuals with better knowledge are more likely to contribute ideas which receive high popularity, i.e., great number of votes and comments, these ideas are usually attract attention of firms and positively influence firm's decisions on the implementation (Schemmann et al., 2016).

Regarding the second characteristic of user interaction, we find that the diversity of an individual's interaction in online innovation community positively influences the 
number of new ideas posted by him/her. In addition, the number of new ideas shows a marginal increasing relationship with the growth of interaction diversity. The findings indicate that participating into the communication of diverse idea categories in OICs stimulates people's productivity of new idea generation. The number of individuals' new ideas increases faster as their interaction diversity increases. Our findings are in line with the results of previous studies on innovation process and idea generation. For example, a study on brainstorming has disclosed that diverse interaction can stimulate associations in memory that lead to idea generation (Osborn, 1953). Our study provides the evidence that the stimulation effect of diverse interaction on ideation effort exists for online behaviours in online communities as well. As different categories of ideas posted on the communities represent different "thought worlds" (Dougherty, 1992), having interaction in those categories means the access to a bundle of diverse knowledge. This provides people increased recombination opportunities for creating new ideas, which may lead to a marginally growth of individuals' innovation outcomes.

Finally, our results illustrate that interaction diversity has a negative influence on the number of implemented ideas. This indicates that, instead of benefiting from diverse interaction, individuals who participated into more diverse interactions with other users in OICs may have fewer implemented ideas posted by them. In other words, having a diverse interaction in OICs may reduce the number of implemented ideas. This challenges the findings of the study by Bayus (2013), who found that "an individual's likelihood of proposing an implemented idea is positively related to the diversity of their past comments on other's ideas". The research object in Bayus's study is the Dell's IdeaStorm community, which attracts ideas from mainly ordinary PC users. The OIC we analysed in this research is the Microsoft innovation platform for crowdsourcing ideas of Microsoft's Business Intelligent products. Because the characteristics of the products in these two communities are totally different, these two communities attract very different kinds of crowds. Comparing with the users in Dell's IdeaStorm community, users in Microsoft's OIC have to gain more professional and technical knowledge 
in order to contribute valuable ideas. Thus, diverse knowledge may create more opportunities for users in Dell's IdeaStorm community to produce innovative ideas which turn out to be valuable, but may not be helpful for the users in Microsoft's OIC as gaining in-depth knowledge is found to be more important in our study. Due to the limitation of time allocation to the information processing activities (Ocasio, 1997), the increase in the diversity of interaction may reduce the time which can be allocated to each of the segmented areas. Indeed, an individual's diverse interaction in OICs negatively influences the number of implemented ideas posted by them. However, it is worth noting that our results also detected that this negative influence only occurs when users are already actively involved into the online innovation process that at least one posted idea has been implemented. In other words, without active interaction in OICs, only reducing interaction diversity may not help customers increase the number of implemented ideas.

\subsection{Implications}

This research involving an analysis of individual-level online behaviours in OICs, is a first step to address the key question of whether users' innovation contribution can be influenced by their online interaction with others. The results we received from the empirical analysis show a number of significant implications for managerial practices. First, this study suggests that besides encouraging users to post more ideas, host firms should pay attention to the creation of an active communication environment where users are actively involved in the online interactions. As discussed in the present study, increasing the amount of online interaction among users can increase both the number of posted ideas and the number of implemented ideas. Firms can consider exploiting reward mechanisms for incentivising such interaction, for example, mechanisms using virtual badge awards can be applied in order to award users who exhibit active interaction behaviours (Fiedler \& Sarstedt, 2014). 
Second, this research suggests that the management on guiding how much interaction is appropriate is essential as spending too much time on interaction may reduce customer's productivity of generating new ideas. Moreover, firms should pay attention to the diversity of peer interaction, which is negatively related to the number of implemented ideas, although it helps to incentivize more ideas generated from customers. If the interactions are not properly guided towards having them focused in a limited number of product categories, firms may fail to collect quality ideas from crowdsourcing. Therefore, for the OICs which are similar to Microsoft's platform where users possess professional and technical knowledge, firms should encourage users to develop good depth peer interaction in focused areas, in order to increase the number of quality ideas.

Third, it is worth noticing that the effect of interaction diversity on the number of implemented ideas is based on the fact that the individuals already had a reasonable amount of interaction in OICs. In other words, simply reducing the diversity of interaction without considering the amount of interaction the user has already made would not help individuals increase the number of their implemented ideas. Therefore, the management of OICs should encourage users to develop continuous interaction and at the same time, control their interaction scope to focused categories. This guideline is especially important to new users who usually need motivation to stimulate their further involvement and contribution in OICs. Such motivation normally comes from the implementation of their ideas by host firms.

\subsection{Limitations and future research}

Besides the characteristics we selected in this research, there are other characteristics of user interaction that may affect individuals' innovation contribution, such as the emotions created via peer interactions. Based on the emotions that interactions contain, comments provided by users may be divided into different types, such as positive (con- 
structive) and negative (destructive) as well as neutral comments. Positive comments may motivate users to further work on idea generation. Negative comments might have a negative effect on users' motivation. Therefore, studies on these characteristics may lead to the development of new hypotheses and, consequently, a deeper understanding of how the nature of user interaction influences crowdsourced ideation. Moreover, since only the number of posted ideas and the number of implemented ideas are employed as the characteristics of a user's innovation outcomes in this study, studies on other characteristics are needed in future research. For example, a user's contributed ideas can be categorized through automated text-mining method in order to identify more detailed characteristics, which might lead to interesting contingency effects. Another limitation comes from the employed analytical approach in this research. While the static approach is acceptable for examining the research questions, the use of a longitudinal analytical approach might disclose more comprehensive results, such as how an ideator's innovation capability changes along with his/her continuous participation in peer interactions on OICs. In addition, OICs only represent one type of crowdsourcing platform. User behaviors in other platforms, such as one-time contest crowdsourcing may exhibit differently and show different results. Future studies could, therefore, attempt to find out whether a similar type of relationship between peer interaction and innovation outcomes found from OICs exists in other crowdsourcing contexts.

Further to the findings we obtained from this study, future research to discover the cause behind the relationship of user interaction and innovation production can be interesting. For example, a qualitative study could be conducted to disclose why individuals' interactions can increase the number of their implemented ideas. Moreover, as our results contradict that other research factors such as product characteristics and types of consumers may affect the examined relationship, empirical studies are necessary to disclose that how the other research factors affect the relationship between user interaction and innovation performance. 


\section{Conclusion}

OICs have been increasingly receiving great attention from firms as a new way to facilitate firm's innovation development. In the form of digital platforms, OICs crowdsource new product ideas directly from customers, and enable customers to interact with each other about products and services innovation. Although many firms have developed and launched the digital innovation platforms, very little is know about the influence of peer interaction among customers on their innovation contribution. This empirical study of Microsoft's Idea community reveal that peer interaction helps increase the number of implemented ideas, but has an inverted U-shaped relationship with idea numbers. Moreover, users benefit from interacting in more idea categories as users become much more motivated in idea generation. However, the negative effect

of the diverse interaction is that the number of implemented ideas decreases, because users on Microsoft's Idea community are skilled and knowledgeable customers who need to be focused to be able to contribute valuable ideas. These findings highlight the importance of managing peer interaction on digital innovation platforms and provide managerial guidance on incentivising specific interaction behaviours in order to make firm's innovation development more effectively.

\section{References}

Algesheimer, R., Dholakia, U. M., \& Herrmann, A. (2005). The social influence of brand community: Evidence from european car clubs. Journal of marketing, $69(3), 19-34$.

Amabile, T. M. (1996). Creativity in context: Update to the social psychology of creativity. Hachette UK. 
Anderson, T., Liam, R., Garrison, D. R., \& Archer, W. (2001). Assessing teaching presence in a computer conferencing context.

Bayus, B. L. (2013). Crowdsourcing new product ideas over time: An analysis of the dell ideastorm community. Management science, 59(1), 226-244.

Bullinger, A. C., Neyer, A.-K., Rass, M., \& Moeslein, K. M. (2010). Communitybased innovation contests: Where competition meets cooperation. Creativity and innovation management, 19(3), 290-303.

Burt, R. S., et al. (2005). Brokerage and closure: An introduction to social capital. Oxford university press.

Carlile, P. R. (2004). Transferring, translating, and transforming: An integrative framework for managing knowledge across boundaries. Organization science, $15(5), 555-568$.

Cheung, Y. B. (2002). Zero-inflated models for regression analysis of count data: a study of growth and development. Statistics in medicine, 21(10), 1461-1469.

Csikszentmihalyi, M. (1997). Flow and the psychology of discovery and invention. HarperPerennial, New York, 39.

Dahlander, L., \& Frederiksen, L. (2012). The core and cosmopolitans: A relational view of innovation in user communities. Organization science, 23(4), 988-1007.

Dahlander, L., \& O’Mahony, S. (2011). Progressing to the center: Coordinating project work. Organization science, 22(4), 961-979. 
Di Gangi, P. M., \& Wasko, M. (2009). Steal my idea! organizational adoption of user innovations from a user innovation community: A case study of dell ideastorm. Decision Support Systems, 48(1), 303-312.

Dougherty, D. (1992). Interpretive barriers to successful product innovation in large firms. Organization science, 3(2), 179-202.

Fiedler, M., \& Sarstedt, M. (2014). Influence of community design on user behaviors in online communities. Journal of Business Research, 67(11), 22582268.

Figallo, C. (1998). Hosting web communities: Building relationships, increasing customer loyalty, and maintaining a competitive edge.

Franke, N., \& Shah, S. (2003). How communities support innovative activities: an exploration of assistance and sharing among end-users. Research policy, 32(1), 157-178.

Gebauer, J., Füller, J., \& Pezzei, R. (2013). The dark and the bright side of co-creation: Triggers of member behavior in online innovation communities. Journal of Business Research, 66 (9), 1516-1527.

Girotra, K., Terwiesch, C., \& Ulrich, K. T. (2010). Idea generation and the quality of the best idea. Management science, 56(4), 591-605.

Glen, U. L., \& Hauser, J. R. (1993). Design and marketing of new products. Prentice Hall, Englewood Cliffs, NJ.

Greene, W. (1994). Accounting for excess zeros and sample selection in poisson and negative binomial regression models (Working Papers). New York University, Leonard N. Stern School of Business, Department of Economics. 
Harrison, D. A., \& Klein, K. J. (2007). What's the difference? diversity constructs as separation, variety, or disparity in organizations. Academy of management review, 32(4), 1199-1228.

Heilbron, D. C. (1994). Zero-altered and other regression models for count data with added zeros. Biometrical Journal, 36(5), 531-547.

Hinsz, V. B., Tindale, R. S., \& Vollrath, D. A. (1997). The emerging conceptualization of groups as information processors. Psychological bulletin, 121(1), 43.

Hofstetter, R., Aryobsei, S., \& Herrmann, A. (2018). Should you really produce what consumers like online? empirical evidence for reciprocal voting in open innovation contests. Journal of Product Innovation Management, 35(2), 209229.

Hoornaert, S., Ballings, M., Malthouse, E. C., \& Van den Poel, D. (2017). Identifying new product ideas: waiting for the wisdom of the crowd or screening ideas in real time. Journal of Product Innovation Management, 34(5), 580597.

Howe, J. (2006). The rise of crowdsourcing. Wired magazine, 14(6), 1-4.

Jeppesen, L. B., \& Lakhani, K. R. (2010). Marginality and problem-solving effectiveness in broadcast search. Organization science, 21(5), 1016-1033.

Kaye, B. K., \& Johnson, T. J. (2002). Online and in the know: Uses and gratifications of the web for political information. Journal of Broadcasting \& Electronic Media, 46(1), 54-71. 
Kohn, N. W., Paulus, P. B., \& Choi, Y. (2011). Building on the ideas of others: An examination of the idea combination process. Journal of Experimental Social Psychology, 47(3), 554-561.

Kohn, N. W., \& Smith, S. M. (2011). Collaborative fixation: Effects of others' ideas on brainstorming. Applied Cognitive Psychology, 25(3), 359-371.

Koput, K. W. (1997). A chaotic model of innovative search: some answers, many questions. Organization Science, 8(5), 528-542.

Liao, S., \& Cheng, C. C. (2014). Brand equity and the exacerbating factors of product innovation failure evaluations: A communication effect perspective. Journal of business research, 67(1), 2919-2925.

Magee, J. C., \& Galinsky, A. D. (2008). 8 social hierarchy: The self-reinforcing nature of power and status. Academy of Management annals, 2(1), 351-398.

Mahr, D., \& Lievens, A. (2012). Virtual lead user communities: Drivers of knowledge creation for innovation. Research policy, 41(1), 167-177.

Nambisan, S., \& Baron, R. A. (2007). Interactions in virtual customer environments: Implications for product support and customer relationship management. Journal of interactive marketing, 21 (2), 42-62.

Nijstad, B. A., \& Stroebe, W. (2006). How the group affects the mind: A cognitive model of idea generation in groups. Personality and social psychology review, $10(3)$, 186-213.

Ocasio, W. (1997). Towards an attention-based view of the firm. Strategic management journal, 18(S1), 187-206. 
Ogink, T., \& Dong, J. Q. (2017). Stimulating innovation by user feedback on social media: The case of an online user innovation community. Technological Forecasting and Social Change.

Osborn, A. F. (1953). Applied imagination.

Palmgreen, P., Wenner, L. A., \& Rayburn, J. (1981). Gratification discrepancies and news program choice. Communication Research, 8(4), 451-478.

Parker, B. J., \& Plank, R. E. (2000). A uses and gratifications perspective on the internet as a new information source. American Business Review, 18(2), 43.

Paulus, P. B., \& Yang, H.-C. (2000). Idea generation in groups: A basis for creativity in organizations. Organizational behavior and human decision processes, 82(1), 76-87.

Perry-Smith, J. E. (2006). Social yet creative: The role of social relationships in facilitating individual creativity. Academy of Management journal, 49(1), $85-101$.

Perry-Smith, J. E., \& Shalley, C. E. (2003). The social side of creativity: A static and dynamic social network perspective. Academy of management review, 28(1), 89-106.

Perse, E. M., \& Courtright, J. A. (1993). Normative images of communication media mass and interpersonal channels in the new media environment: Mass and interpersonal channels in the new media environment. Human communication research, 19(4), 485-503. 
Podolny, J. M. (2001). Networks as the pipes and prisms of the market. American journal of sociology, 107(1), 33-60.

Rietzschel, E. F., Nijstad, B. A., \& Stroebe, W. (2007). Relative accessibility of domain knowledge and creativity: The effects of knowledge activation on the quantity and originality of generated ideas. Journal of experimental social psychology, 43(6), 933-946.

Rothaermel, F. T., \& Sugiyama, S. (2001). Virtual internet communities and commercial success: individual and community-level theory grounded in the atypical case of timezone. com. Journal of management, 27(3), 297-312.

Sawhney, M., Verona, G., \& Prandelli, E. (2005). Collaborating to create: The internet as a platform for customer engagement in product innovation. Journal of interactive marketing, 19(4), 4-17.

Schemmann, B., Herrmann, A. M., Chappin, M. M., \& Heimeriks, G. J. (2016). Crowdsourcing ideas: Involving ordinary users in the ideation phase of new product development. Research Policy, 45 (6), 1145-1154.

Simon, H., \& March, J. (1958). Organization. N.- Y.

Simon, H. A., \& Barnard, C. I. (1947). Administrative behavior: A study of decision-making processes in administrative organization. Macmillan.

Simons, J. S., Neal, D. J., \& Gaher, R. M. (2006). Risk for marijuana-related problems among college students: An application of zero-inflated negative binomial regression. The American Journal of Drug and Alcohol Abuse, 32(1), $41-53$. 
Smith, S. M. (2003). The constraining effects of initial ideas. Group creativity: Innovation through collaboration, 15-31.

Stafford, T. F., Stafford, M. R., \& Schkade, L. L. (2004). Determining uses and gratifications for the internet. Decision sciences, 35(2), 259-288.

Terwiesch, C., \& Xu, Y. (2008). Innovation contests, open innovation, and multiagent problem solving. Management science, 54 (9), 1529-1543.

Uzzi, B. (1997). Social structure and competition in interfirm networks: The paradox of embeddedness. Administrative science quarterly, 35-67.

Vuong, Q. H. (1989). Likelihood ratio tests for model selection and non-nested hypotheses. Econometrica: Journal of the Econometric Society, 307-333.

West, J., \& Lakhani, K. R. (2008). Getting clear about communities in open innovation. Industry and Innovation, 15(2), 223-231. 
Table 1: Related work on OICs

\begin{tabular}{|c|c|c|}
\hline Name & Journal & Key findings \\
\hline $\begin{array}{l}\text { Ma et al. } \\
(2019)\end{array}$ & $\begin{array}{l}\text { Decision Support } \\
\text { Systems }\end{array}$ & $\begin{array}{l}\text { This study examined the differences between adopted } \\
\text { and non-adopted user innovations. They find that the } \\
\text { popularity, integrity and maintenance of the innova- } \\
\text { tion, as well as the prior adoption experience of the } \\
\text { innovator, positively influence the adoption of a user } \\
\text { innovation by the firm. }\end{array}$ \\
\hline $\begin{array}{l}\text { Yan et al. } \\
(2018)\end{array}$ & $\begin{array}{l}\text { Journal of Man- } \\
\text { agement Informa- } \\
\text { tion Systems }\end{array}$ & $\begin{array}{l}\text { This study looked at the role of internal employees of } \\
\text { the host firm on its OIC's long term success. They find } \\
\text { that ideas contributed and promoted by employees are } \\
\text { more likely to be implemented than those contributed } \\
\text { and only promoted by product users. }\end{array}$ \\
\hline $\begin{array}{l}\text { Hoornaert } \\
\text { et al. } \\
(2017)\end{array}$ & $\begin{array}{l}\text { Journal of Prod- } \\
\text { uct Innovation } \\
\text { Management }\end{array}$ & $\begin{array}{l}\text { This study proposed a model that can assist managers } \\
\text { in efficiently processing crowdsourced ideas by iden- } \\
\text { tifying the aspects of ideas that are most predictive } \\
\text { of future implementation. The results indicate that } \\
\text { crowd feedback is the best predictor of idea implemen- } \\
\text { tation, followed by idea content and distinctiveness, } \\
\text { and the contributor's past idea-generation experience. }\end{array}$ \\
\hline $\begin{array}{l}\text { Oginkand } \\
\text { Dong(2017) }\end{array}$ & $\begin{array}{l}\text { Technological } \\
\text { Forecasting and } \\
\text { Social Change }\end{array}$ & $\begin{array}{l}\text { This research studied that how other users' feedback } \\
\text { may stimulate a focal user's contribution to OICs. } \\
\text { They identified multifaceted benefits from user feed- } \\
\text { back that are cognitive, integrative and affective in the } \\
\text { archival comments received by a focal user. }\end{array}$ \\
\hline $\begin{array}{l}\text { Li et al. } \\
(2016)\end{array}$ & $\begin{array}{l}\text { Decision Support } \\
\text { Systems }\end{array}$ & $\begin{array}{l}\text { This study examined the determinants of firms' imple- } \\
\text { mentation of ideas from OICs. The results show sig- } \\
\text { nificant impacts of characteristics including the con- } \\
\text { tributor's prior participation and prior implementa- } \\
\text { tion rate, as well as the idea's popularity, length, and } \\
\text { supporting evidence on idea implementation likelihood } \\
\text { and also reveal important differences in their effects for } \\
\text { hybrid versus professional OICs. }\end{array}$ \\
\hline $\begin{array}{l}\text { Schemmann } \\
\text { et al.(2016) }\end{array}$ & Research Policy & $\begin{array}{l}\text { This study investigated which ideator and idea-related } \\
\text { characteristics determine whether an idea is imple- } \\
\text { mented by a host firm. The results reveal that ideators } \\
\text { paying major attention to crowdsourced ideas of oth- } \\
\text { ers, the idea popularity, as well as its potential in- } \\
\text { novativeness positively influence whether an idea is } \\
\text { implemented by the firm. }\end{array}$ \\
\hline
\end{tabular}




\begin{tabular}{|l|l|l|}
\hline $\begin{array}{l}\text { Dong and } \\
\text { Wu (2015) }\end{array}$ & $\begin{array}{l}\text { Journal of Strate- } \\
\text { gic Information } \\
\text { Systems }\end{array}$ & $\begin{array}{l}\text { This research studied the extent to which firms are } \\
\text { able to derive business value from OICs. The results } \\
\text { show that OIC-enabled ideation capability does not } \\
\text { influence firm value, whereas OIC-enabled implemen- } \\
\text { tation capability increases firm value. }\end{array}$ \\
\hline $\begin{array}{l}\text { Fiedler } \\
\text { and Sarst- } \\
\text { edt(2014) }\end{array}$ & $\begin{array}{l}\text { Journal of Busi- } \\
\text { ness Research } \\
\text { This study focused on how community design influ- } \\
\text { ences user behavior in online communities. The results } \\
\text { show that common identity attachment is the primary } \\
\text { driver of user behavior in online communities. }\end{array}$ \\
\hline $\begin{array}{l}\text { Dahlander } \\
\text { and Fred- } \\
\text { erikse } \\
(2012)\end{array}$ & $\begin{array}{l}\text { Organization sci- } \\
\text { ence }\end{array}$ & $\begin{array}{l}\text { This research analyzed the extent to which people po- } \\
\text { sitioned within the core of an community as well as } \\
\text { people that are cosmopolitans positioned across mul- } \\
\text { tiple external communities affect innovation. }\end{array}$ \\
\hline $\begin{array}{l}\text { Mahr and } \\
\text { Lievens }(2012\end{array}$ & Research policy & $\begin{array}{l}\text { This study examined lead users' potential impact on } \\
\text { the development of valuable innovation knowledge in } \\
\text { OICs. They find that Lead users' technical expertise } \\
\text { makes them particularly well-suited to develop new } \\
\text { functionalities, but less so for design and usability im- } \\
\text { provements. }\end{array}$ \\
\hline
\end{tabular}

Table 2: PowerBI user population

\begin{tabular}{|c|c|c|c|}
\hline \multicolumn{4}{|c|}{$\begin{array}{c}\text { Idea contributors: } \\
5468 \text { individuals } \\
9243 \text { ideas } \\
559 \text { implemented ideas }\end{array}$} \\
\hline \multicolumn{2}{|c|}{$\begin{array}{l}\text { One-time contributor } \\
3909 \text { individuals } \\
3909 \text { ideas }\end{array}$} & \multicolumn{2}{|c|}{$\begin{array}{l}\text { Serial contributor } \\
1559 \text { individuals } \\
5334 \text { ideas }\end{array}$} \\
\hline $\begin{array}{l}\text { Zero idea implemented } \\
3713 \text { individuals } \\
3713 \text { ideas }\end{array}$ & $\begin{array}{c}\text { One idea implementec } \\
196 \text { individuals } \\
196 \text { ideas }\end{array}$ & $\begin{array}{c}\text { Zero idea implemented } \\
1305 \text { individuals } \\
4971 \text { ideas }\end{array}$ & $\begin{array}{c}\text { One or more ideas implemented } \\
254 \text { individuals } \\
363 \text { ideas }\end{array}$ \\
\hline
\end{tabular}

Table 3: User interaction behaviours

\begin{tabular}{|c|c|c|}
\hline \multicolumn{3}{|c|}{$\begin{array}{l}\text { Idea contributors: } \\
5468 \text { individuals } \\
5019 \text { comments }\end{array}$} \\
\hline Zero comment & One to five comments & Over five comments \\
\hline 3892 individuals & 1377 individuals & 199 individuals \\
\hline 0 comment & 2573 comments & 2446 comments \\
\hline
\end{tabular}


Table 4: Descriptive statistics

\begin{tabular}{lcccc}
\hline & Mean & S.D. & Min & Max \\
\hline Number of ideas & 4.458 & 6.476 & 1 & 45 \\
Number of implemented ideas & 0.288 & 0.811 & 0 & 8 \\
Number of comments & 2.975 & 6.577 & 0 & 49 \\
Comments diversity & 0.139 & 0.239 & 0 & 0.982 \\
\hline
\end{tabular}

Table 5: Correlations

\begin{tabular}{lcccc}
\hline & Number of comments & Number of ideas & Number of implemented ideas & Comments diversity \\
\hline Number of comments & 1 & & & \\
Number of ideas & $0.800^{* * *}$ & 1 & 1 & 1 \\
Number of implemented ideas & $0.331^{* * *}$ & $0.478^{* * *}$ & $0.286^{* * *}$ & 1 \\
Comments diversity & $0.791^{* * *}$ & $0.699^{* * *}$ &
\end{tabular}

Table 6: Hierarchical regression analysis on $\mathrm{H} 1$

\begin{tabular}{|c|c|c|c|c|c|c|}
\hline \multirow[t]{2}{*}{ Model } & \multirow[t]{2}{*}{ Adjusted R-Squared } & \multirow[t]{2}{*}{ Sig. (ANONA) } & \multirow[t]{2}{*}{ Terms } & \multicolumn{3}{|c|}{ Hierarchical Regression } \\
\hline & & & & Std.coef & $\mathrm{T}$ value & Sig. \\
\hline \multirow[t]{2}{*}{ Model 1: $y_{q t y}=\beta_{0}+\beta_{1} x_{N o}+\epsilon$} & \multirow[t]{2}{*}{0.641} & \multirow[t]{2}{*}{$* * *$} & constant & 2.113 & 47.680 & $* * *$ \\
\hline & & & $x_{N o}$ & 0.788 & 128.340 & $* * *$ \\
\hline \multirow[t]{3}{*}{ Model 2: $y_{q t y}=\beta_{0}+\beta_{1} x_{N o}+\beta_{2} x_{N o}^{2}+\epsilon$} & \multirow[t]{3}{*}{0.665} & \multirow[t]{3}{*}{$* * *$} & constant & 1.716 & 37.730 & $* * *$ \\
\hline & & & $x_{N o}$ & 1.117 & 79.620 & $* * *$ \\
\hline & & & & -0.011 & -25.890 & $* * *$ \\
\hline \multirow[t]{3}{*}{ Model 3: $y_{q t y}=\beta_{0}+\beta_{1} x_{N o}+\beta_{2} e^{x_{N o}}+\epsilon$} & \multirow[t]{3}{*}{0.666} & \multirow[t]{3}{*}{$* * *$} & constant & 2.003 & 46.630 & $* * *$ \\
\hline & & & $x_{N o}$ & 0.842 & 134.340 & $* * *$ \\
\hline & & & $e^{x_{N o}}$ & $-1.224 \mathrm{e}-20$ & -26.320 & $* * *$ \\
\hline
\end{tabular}

Table 7: Zero-inflated negative binomial estimation results on $\mathrm{H} 2$ and $\mathrm{H} 4$

\begin{tabular}{|c|c|c|c|c|c|c|c|c|}
\hline \multirow[b]{2}{*}{ Variable } & \multicolumn{2}{|c|}{ Model 4} & \multicolumn{2}{|c|}{ Model 5} & \multicolumn{2}{|c|}{ Model 6} & \multicolumn{2}{|c|}{ Model 7} \\
\hline & Coeff. & $\mathrm{SE}$ & Coeff. & SE & Coeff. & SE & Coeff. & SE \\
\hline \multicolumn{9}{|l|}{ Negative binomial part: } \\
\hline Constant & $-0.492 * * *$ & 0.059 & $-1.678^{* * *}$ & 0.032 & $-0.390 * * *$ & 0.071 & $-1.830^{* * *}$ & 0.036 \\
\hline$x_{N o}:$ number of comments & $0.023^{* * *}$ & 0.003 & $0.083^{* * *}$ & 0.003 & $0.028^{* * *}$ & 0.004 & $0.034^{* * *}$ & 0.005 \\
\hline$x_{d i v}:$ comment diversity & & & & & $-0.357^{*}$ & 0.164 & $1.760^{* * *}$ & 0.155 \\
\hline \multicolumn{9}{|l|}{ Zero-inflated part: } \\
\hline Constant & $1.246^{* * *}$ & 0.078 & & & $1.348^{* * *}$ & 0.085 & & \\
\hline$x_{N o}:$ number of comments & $-0.437 * * *$ & 0.038 & & & $-0.482^{* * *}$ & 0.062 & & \\
\hline$x_{d i v}:$ comment diversity & & & & & 0.309 & 0.694 & & \\
\hline Dispersion parameter & 1.074 & & 0.324 & & 1.151 & & 0.355 & \\
\hline Log-likelihood & -5450 & & -5704 & & -5447 & & -5647 & \\
\hline
\end{tabular}

***: p-value <0.001; **: p-value <0.01; ${ }^{*}$ : p-value $<0.05$;

Dependent variable: number of implemented ideas 
Table 8: Vuong test results

\begin{tabular}{llll}
\hline & Vuong z-statistic & H_A & p-value \\
\hline Raw & 11.733 & model4>model5 & $* * *$ \\
AIC-corrected & 11.641 & model4 $>$ model5 & $* * *$ \\
BIC-corrected & 11.312 & model4 $>$ model5 & $* * *$ \\
\hline Raw & -9.248 & model6 $>$ model7 & $* * *$ \\
AIC-corrected & -9.109 & model6 $>$ model7 & $* * *$ \\
BIC-corrected & -8.613 & model6 $>$ model7 & $* * *$ \\
\hline$* * * . \quad$ p-value $<0.001$ & & &
\end{tabular}

Table 9: Hierarchical regression analysis on H3

\begin{tabular}{|c|c|c|c|c|c|c|}
\hline \multirow[t]{2}{*}{ Model } & \multirow[t]{2}{*}{ Adjusted R-Squared } & \multirow[t]{2}{*}{ Sig. (ANONA) } & \multirow[t]{2}{*}{ Terms } & \multicolumn{3}{|c|}{ Hierarchical Regression } \\
\hline & & & & Std.coef & $\mathrm{T}$ value & Sig. \\
\hline \multirow[t]{4}{*}{ Model 8: $y_{q t y}=\beta_{0}+\beta_{1} x_{N o}+\beta_{2} e^{x_{N o}}+\beta_{3} x_{d i v}+\epsilon$} & \multirow[t]{4}{*}{0.667} & \multirow[t]{4}{*}{ **** } & constant & 1.828 & 40.420 & $* * *$ \\
\hline & & & $x_{N o}$ & 3.254 & 11.134 & *** \\
\hline & & & $e^{x_{N o}}$ & -211.077 & 65.910 & *** \\
\hline & & & & 18.911 & 17.700 & *** \\
\hline \multirow[t]{5}{*}{ Model 9: $y_{q t y}=\beta_{0}+\beta_{1} x_{N o}+\beta_{2} e^{x_{N o}}+\beta_{3} x_{d i v}+\beta_{4} x_{d i v}^{2}+\epsilon$} & \multirow[t]{5}{*}{0.671} & \multirow[t]{5}{*}{$* * *$} & constant & 2.140 & 39.148 & *** \\
\hline & & & $x_{N o}$ & 3.452 & 24.774 & *** \\
\hline & & & $e^{x_{N o}}$ & -224.324 & -20.157 & *** \\
\hline & & & & 0.514 & 0.747 & *** \\
\hline & & & & 29.295 & 27.835 & *** \\
\hline \multirow{5}{*}{ Model 10: $y_{q t y}=\beta_{0}+\beta_{1} x_{N o}+\beta_{2} e^{x_{N o}}+\beta_{3} x_{d i v}+\beta_{4} e^{x_{d i v}}+\epsilon$} & \multirow[t]{5}{*}{0.671} & \multirow[t]{5}{*}{$* * *$} & constant & -36.256 & -25.960 & $* * *$ \\
\hline & & & $x_{N o}$ & 3.270 & 23.400 & *** \\
\hline & & & $e^{x_{N o}}$ & -212.286 & -19.070 & *** \\
\hline & & & $x_{d i v}$ & -34.729 & -17.590 & *** \\
\hline & & & $e^{x_{d i v}}$ & 38.380 & 27.290 & *** \\
\hline
\end{tabular}

